\title{
O DEVER DE CONTROLE DAS EMPRESAS CONCESSIONÁRIAS DE TRANSPORTE COLETIVO SOBRE OS USUÁRIOS: INEXISTÊNCIA DE PODER DE POLÍCIA E NECESSIDADE DE COOPERAÇÃO NO ENFRENTAMENTO DA PANDEMIA DE COVID-19.
}

\section{RESUMO}

As empresas concessionárias de transporte coletivo devem controlar as condutas dos usuários, impondo restrições quanto ao número de passageiros nos veículos e a observância de regras sanitárias. Não há aqui exercício do poder de polícia, mas o cumprimento de regras específicas referentes ao uso de transporte coletivo pelas empresas que prestam os serviços e pelos usuários. Especialmente durante a pandemia de COVID-19, essas obrigações ganham importância para evitar que os ônibus sejam vetores de contaminação do vírus. Isso não exclui a cooperação do Poder Público e a atuação dos agentes de trânsito e segurança, mesmo se sanções forem necessárias.

Palavras-chave: Transporte coletivo; concessionárias de serviço público; COVID-19; Poder de polícia; cooperação.

\section{THE DUTY OF PUBLIC TRANSPORT COMPANIES TO CONTROL USERS: LACK OF ADMINISTRATIVE POLICING POWER AND NEED FOR COOPERATION TO COMBAT COVID-19 PANDEMIC}

\begin{abstract}
Public transportation companies must control the user's behavior, imposing restrictions on the number of passengers in vehicles and the observance of health rules. There is no exercise of administrative policing power here, but compliance with specific rules that regards the use of public transport by the companies and by the users. Especially in the COVID-19 pandemic, these obligations take on special importance in order to prevent buses from being vectors of virus contamination. This does not exclude the cooperation of the Government and the action of traffic and security agents, especially if necessary to impose sanctions.
\end{abstract}

Key-words: Public transport; Public service concessionaires; COVID-19; Administrative Policing Power; Cooperation

\section{INTRODUÇÃO, OBJETIVOS E METODOLOGIA}

\footnotetext{
${ }^{1}$ Doutorando em Direito Fiscal pela Universidade de Lisboa. Mestre em Direito Tributário e Direitos Humanos pela Universidade Federal do Pará. Professor da Unama (Universidade da Amazônia). Defensor Público do Estado do Pará.
} 
Com o advento da Pandemia de COVID-19, passou a ser imperiosa a adoção de distanciamento social, assim como a tentativa de evitar aglomerações de pessoas. Tais medidas, amplamente recomendadas pela comunidade científica internacional e pela Organização Mundial da Saúde (OMS), se voltam justamente à tentativa de evitar a propagação desenfreada do vírus na população e, consequentemente, o colapso nos sistemas de saúde e a elevação do número de óbitos. Com isso, os entes federados, após as decretações de calamidades públicas em seus respectivos territórios, passam a editar decretos com restrições à circulação e aglomeração de pessoas, assim como limitações a atividades econômicas.

Por via de consequência, os entes federados passam, investidos no Poder de Polícia, a impor multas às pessoas físicas que violem as regras de distanciamento social, medidas sanitárias e de higienização, como o uso de máscaras. Aos estabelecimentos comerciais exploradores de atividades econômicas, além das limitações de horário de funcionamento e de número de clientes, são impostos, como condicionantes ao seu funcionamento, protocolos de proteção sanitária, como a disponibilização de álcool em gel aos consumidores e a observância de distância mínima entre os usuários. Em caso de descumprimento, os agentes econômicos também ficam sujeitos às penalidades pecuniárias e mesmo à interdição de seus estabelecimentos. Em igual sentido, os concessionários de serviços públicos devem observar as medidas de prevenção à propagação da COVID-19, com especial atenção aos protocolos estabelecidos pelos entes federados. Mais do que isso, os concessionários dos serviços públicos, além de zelar pelas condutas de seus prepostos e representantes, passam a ser obrigados a controlar a conduta dos usuários dos serviços públicos. Assim, evitando que haja o ingresso massivo de pessoas nos estabelecimentos e nos veículos respectivos, assim como que usuários fiquem em seu interior sem o uso de máscaras, os concessionários também zelam pela garantia da ordem e da saúde públicas.

Não obstante isso, as concessionárias de serviços públicos nem sempre obtém efetividade no controle do comportamento de seus usuários, o que, em parte se justifica pela baixa adesão da população brasileira ao distanciamento social. Tal cenário decorre tanto de questões socioeconômicas, como culturais, além da intensa politização da pandemia e suas medidas de contenção no Brasil. A questão ganha sensível gravidade no tocante ao transporte coletivo de passageiros nas grandes cidades brasileiras, onde, mesmo na vigência de medidas 
restritivas mais severas, inclusive quando da decretação de lockdowns, os ônibus permaneceram lotados, com aglomeração de passageiros no seu interior e nos pontos de espera.

Uma vez interpelados, como estratégia de defesa, as empresas concessionárias de transporte coletivo e os sindicatos patronais respectivos passaram a sustentar a tese de que não seriam revestidos do poder de polícia para impedir o ingresso de passageiros que eventualmente insistam em subir nos coletivos. Inclusive, pugnam que não podem coagir os usuários a observarem as normas sanitárias no interior dos veículos e que os rodoviários e demais agentes empregados das empresas de transporte coletivo não teriam como, coercitivamente, proibir o acesso de passageiros, inferindo que tal função caberia tão somente ao Poder Público. Desta forma, citam a necessidade de controle dos usuários pela Polícia Militar, cujo poder de restrição sobre saúde e segurança não poderia ser delegado às empresas concessionárias do transporte de passageiros.

Diante desse cenário, pretende-se discutir, no presente trabalho, a robustez jurídica desses entendimentos levantados pelas empresas concessionárias de transporte coletivo. Especialmente, analisar-se-á se os particulares que exploram serviços públicos de transporte coletivo, ao exigir o cumprimento de medidas sanitárias e a restrição de comportamentos dos usuários, estariam exercendo poder de polícia ou se, ao contrário, atuariam em colaboração ao Poder Público na consecução de prevenção e combate à Pandemia de COVID-19, que já perdura, com graves consequências há mais de um ano no Brasil.

Pretende-se adotar o método analítico-dedutivo, com a análise de dispositivos da Constituição Federal, de leis federais sobre transporte coletivo, concessão de serviço público e, para ilustrar, leis locais que tratem da temática. No mais, serão referenciados precedentes da jurisprudência dos tribunais superiores e locais, especialmente após a deflagração da Pandemia de COVID-19, além de levantamento bibliográfico da doutrina jurídica, especialmente no âmbito do Direito Administrativo.

\section{PODER DE POLÍCIA E CONCESSIONÁRIAS DE SERVIÇO PÚBLICO}

Inicialmente, cabe inferir que o Poder de Polícia é entendido como um conjunto de atribuições concedidas à Administração para disciplinar e restringir, em favor do interesse 
público, direitos e liberdades individuais (TÁCITO, 1975). Assim, o poder de polícia ${ }^{2}$ é manifesto em medidas de controle das atividades privadas e de direitos individuais pelo Estado.

Assim, o poder de polícia, classicamente consiste em atos de competência privativa dos entes da Administração e que não podem ser delegados a atores privados ${ }^{3}$. A vedação a delegação do poder de polícia a particulares decorre de que, no Estado Democrático de Direito, as restrições a direitos individuais e o exercício legal da violência configuram monopólio estatal, não podendo ser admitida a imposição coercitiva de deveres por terceiros (JUSTEN FILHO, 2012, p. 566).

Portanto, cabe precipuamente aos órgãos de segurança pública, tal como a Polícia Militar e a Polícia Civil, o controle e a imposição de penalidades quando estiverem violadas regras de proteção à saúde e higiene públicas. Não obstante isso, o Supremo Tribunal Federal fixou a tese de repercussão geral 532 (RE 633782. Data: 26/10/2020), pela qual:

É constitucional a delegação do poder de polícia, por meio de lei, a pessoas jurídicas de direito privado integrantes da Administração Pública indireta de capital social majoritariamente público que prestem exclusivamente serviço público de atuação própria do Estado e em regime não concorrencial.

É competente para executar dada medida administrativa quem for competente para legislar sobre determinada matéria (MEIRELLES, 2005, p. 131). Portanto, os Municípios têm seu campo de atuação específica de polícia administrativa no que tange ao seu particular interesse, notadamente sobre as matérias previstas no art. $30 \mathrm{da} \mathrm{CF} / 88$, que perfazem os

\footnotetext{
${ }^{2}$ Um dos conceitos de Poder de Polícia mais aceitos pela doutrina consta do art. 78 do Código Tributário Nacional, da seguinte forma: "Considera-se poder de polícia atividade da administração pública que, limitando ou disciplinando direito, interesse ou liberdade, regula a prática de ato ou abstenção de fato, em razão de interesse público concernente à segurança, à higiene, à ordem, aos costumes, à disciplina da produção e do mercado, ao exercício de atividades econômicas dependentes de concessão ou autorização do Poder Público, à tranquilidade pública ou ao respeito à propriedade e aos direitos individuais ou coletivos." Em âmbito local, o Código de Posturas do Município de Belém (Lei 7.055/77), o art. $1^{\circ}$, $\$ 1^{\circ}$ preceitua que: "Considera-se poder de polícia a atividade da administração pública, que, limitando ou disciplinando direito, interesse ou liberdade, regula a prática de ato, em razão de interesse público, concernente à segurança, à higiene, à ordem, aos costumes, à disciplina da produção do mercado e ao respeito à propriedade, aos direitos individuais ou coletivos, e ao exercício de atividades econômicas dependentes de concessão ou autorização do poder público, no território do Município"

${ }^{3}$ Como fundamento desse preceito, o Supremo Tribunal Federal, em julgamento da ADI 1.717, entendeu por inconstitucional o art. 58 da Lei 9.649/98, que permitia a fiscalização de profissões regulamentadas por meio de entidades privadas caráter privado, mediante por delegação do poder público e autorização legislativa (Tribunal Pleno, j. em 7-11-02, DJ de 28-3-03, p. 61).
} 
assuntos locais, abrangendo aqueles sobre a população e sobre os serviços públicos e atividades de exploração econômica relativos à higiene e saúde públicas ${ }^{4}$.

Quando se está diante de concessão de serviços públicos, os entes privados que passam a atuar nessa condição não podem se eximir do dever de controle das atitudes dos passageiros, estando, inclusive, sujeitos ao Poder de Polícia exercido pelo Poder concedente e demais esferas da Administração Pública. Isso decorre, inclusive, dos encargos e responsabilidades outorgados e recebidos quando da concessão para prestar os serviços públicos, conforme dispõe o art. 31 da lei 8.987/95, qual seja a lei de concessões públicas ${ }^{5}$.

Nesse esquema, atos mais drásticos e sancionadores, como a imposição de multas pecuniárias ou mesmo a intervenção do direito penal permanecem a cargo dos entes públicos competentes para tal, pois esses últimos já constituem atos típicos de polícia, indelegáveis ao particular.

Não obstante isso, é possível a delegação de atividades de polícia exclusivamente materiais, desde que não envolvam o exercício de autoridade por um particular sobre outro cidadão, como quando da instalação de infraestrutura e equipamentos necessários à instrumentalização posterior do poder de polícia.

Sobre o assunto, Carvalho Filho (2018, p. 143) infere que, em determinadas situações nas quais se faz necessário o exercício do poder de polícia fiscalizatório (normalmente de caráter preventivo), o Poder Público atribui a pessoas privadas, por meio de contrato, a operacionalização material da fiscalização através de máquinas especiais, como ocorre, por exemplo, na triagem em aeroportos para detectar eventual porte de objetos ilícitos ou proibidos. Nesses casos, não fica o Estado despido do poder de polícia, nem procede a

\footnotetext{
${ }^{4}$ Nesse sentido dispõe o Código de Posturas do Município de Belém (lei 7.055/77): “Art. 25 - Compete à fiscalização municipal zelar pela higiene e saúde públicas, tomando as providências necessárias para evitar e sanar irregularidades que venham a comprometê-las. Art. 26 - As normas do poder de polícia relativas à higiene pública serão fiscalizadas pelos órgãos do setor de saúde do Município, excetuando-se as atinentes à higiene e limpeza dos logradouros públicos, de competência do setor de serviços públicos. Parágrafo Único Enquanto inexistir setor de saúde do Município, ficará responsável pela fiscalização referida neste artigo, através de convênio firmado com a Prefeitura, a Secretaria de Estado de Saúde Pública."

${ }^{5}$ Nesse sentido impõe a referida lei: "Art. 31. Incumbe à concessionária: I - prestar serviço adequado, na forma prevista nesta Lei, nas normas técnicas aplicáveis e no contrato; II - manter em dia o inventário e o registro dos bens vinculados à concessão; III - prestar contas da gestão do serviço ao poder concedente e aos usuários, nos termos definidos no contrato; IV - cumprir e fazer cumprir as normas do serviço e as cláusulas contratuais da concessão; V - permitir aos encarregados da fiscalização livre acesso, em qualquer época, às obras, aos equipamentos e às instalações integrantes do serviço, bem como a seus registros contábeis; VI - promover as desapropriações e constituir servidões autorizadas pelo poder concedente, conforme previsto no edital e no contrato; VII - zelar pela integridade dos bens vinculados à prestação do serviço, bem como segurá-los adequadamente; e VIII - captar, aplicar e gerir os recursos financeiros necessários à prestação do serviço."
} 
qualquer delegação, mas apenas atribui ao executor a tarefa de operacionalizar máquinas e equipamentos, sendo-lhe incabível, por conseguinte, instituir qualquer tipo de restrição. $\mathrm{O}$ particular limita-se, com efeito à “constatação de fatos". O mesmo ocorre, aliás, com a fixação de equipamentos de fiscalização de restrições de polícia, como os aparelhos eletrônicos utilizados pelos órgãos de trânsito para a identificação de infrações por excesso de velocidade. Ainda que a fixação e a manutenção de tais aparelhos possam ser atribuídos a pessoas privadas, o poder de polícia continua sendo de titularidade do ente federativo constitucionalmente competente., não se podendo falar em ilicitude quando de semelhante atribuição operacional. Não obstante isso, tais atos devem ser tomados com cautela, tendo em vista a dificuldade de distinguir a mera execução material do efetivo ato de polícia, este privativo do poder público (DI PIETRO, 2018, p. 200).

Portanto, o fato de o ente privado, ser obrigado a orientar e até mesmo regrar a utilização dos serviços públicos pelos indivíduos, quase sempre amparados por normas legais e infralegais, não implica na usurpação do Poder de Polícia, típico da Administração Pública. Pelo contrário, tais atos constituem encargos e deveres dos concessionários dos serviços públicos, compromissos assumidos quando da assunção dos contratos de concessões ou permissão, tendo em vista o zelo pela boa prestação do serviço público. Com isso, resguardase, imediatamente, os direitos dos usuários, mas também os de toda a coletividade.

\section{O CONTROLE DOS USUÁRIOS PELAS EMPRESAS CONCESSIONÁRIAS DE TRANSPORTE COLETIVO COMO ALGO DISTINTO DO PODER DE POLÍCIA}

Inicialmente, cabe ressaltar que, por não ser este o objeto do presente trabalho, não será feita uma delimitação precisa a respeito de se o serviço de transportes coletivo de passageiros configura concessão ou permissão às empresas privadas, uma vez que isso depende das particularidades de legislações locais. Ainda, observam-se confusões práticas entre essas modalidades de prestação do serviço público por particulares ${ }^{6}$. Consideramos que,

\footnotetext{
${ }^{6}$ Conforme ensina Odete Medauar (2018, p. 327), nunca foi fácil a distinção substancial entre concessão e permissão de serviço público, porque ambas implicam prestação de serviços públicos por particulares, com remuneração assegurada pela tarifa que os usuários pagam. Não obstante isso, a concessão se exterioriza, normalmente, por contrato, enquanto a permissão, classicamente, se expressava por ato administrativo, discricionário, precário, revogável, em princípio, a qualquer tempo. Com isso, surge uma outra diferença, já relativamente ao tempo de duração do vínculo: a concessão seria operada por longa duração, enquanto a permissão, por ser precária, teria períodos mais curtos de vigência. Em que pese as diferenças clássicas entre
} 
para o enfrentamento do objeto do presente trabalho - a análise da (im)possibilidade de as empresas que atuam no transporte coletivo de passageiros determinarem medidas de controle sanitário sob os usuários, a fim de diminuir a propagação do Coronavírus - não há grandes consequências no enquadramento do vínculo como concessão, permissão ou autorização de serviço público.

Nesse diapasão, cabe inferir que a lei federal 12.587/13, que trata da Política Nacional de Mobilidade Urbana, no seu art. $9^{\circ}$, parece admitir que o transporte público coletivo de passageiros possa ser objeto de permissão ou de concessão, sempre precedidos por licitação e remunerados por tarifas pagas pelos usuários. Não obstante isso, convencionamos nos referir às empresas que exploram o transporte coletivo como concessionárias, por entender que esta modalidade de delegação, em linhas conceituais, melhor converge com a natureza da prestação do serviço público em testilha. ${ }^{7}$

Em seguida, vale repisar que, em se tratando de transporte coletivo de passageiros dentro do mesmo Município, cabe ao ente federado local, como gestor do sistema de trânsito, o dever de realizar ações relativas ao Poder de Polícia sobre os usuários e sobre os particulares que regularmente operam o referido serviço público no Município ${ }^{8}$.

Portanto, cabe também aos agentes de trânsito das Autarquias Municipais de trânsito ${ }^{9}$ e aos Guardas Municipais ${ }^{10}$ a realização do controle da lotação máxima de passageiros dos

as modalidades, a Constituição Federal, no art. 175, estabeleceu a exigência de licitação para ambas, o que levava a aproximar a permissão da natureza de contrato. No mais, nos termos da lei 8.897/95, a concessão é atribuída às pessoas jurídica ou consórcio de empresas, até por envolver investimentos mais vultosos, enquanto a permissão pode ser conferida a pessoas físicas, por envolver, via de regras, atividades mais simples e/ou com duração precária.

${ }^{7}$ Vale ressalvar que a lei 10.233/01, em seu art. 13, V, “e”, infere que a prestação de serviços de transporte coletivo interestadual e internacional de passageiros deve ocorrer sob a modalidade de autorização.

8 No Município de Belém, o Código de Posturas (lei 7.056/77) preceitua, no seu art. 188, que incumbe à Prefeitura quando ao serviço de transporte urbano nas seguintes vertentes: I - baixar decreto regulamentando o serviço público de transporte coletivo do município; II - promover os meios para a prestação adequada do serviço;

III - fiscalizar a execução do serviço, a aplicação das tarifas e o pagamento do preço público; IV - recomendar os processos mais econômicos e eficazes para a prestação do serviço; V - fiscalizar as condições de higiene e segurança dos veículos.

9 O Poder de Polícia relativo ao trânsito, no Município de Belém, cabe precipuamente à SEMOB (Superintendência de Mobilidade Urbana de Belém), conforme dispõe a lei municipal 8.227/02: Art. 17-A. A SEMOB tem a finalidade de planejar, gerir, executar e avaliar o sistema de mobilidade urbana do Município de Belém, considerando-se atribuições mínimas: I - coordenar, programar e executar a política nacional de transporte público no Município; II - disciplinar, conceder, operar e fiscalizar os serviços de transporte público de passageiros em geral no âmbito do Município; III - desenvolver o planejamento e a programação do Sistema de Transporte Público de Passageiros, integrando-o com as decisões sobre planejamento urbano do Município de Belém e no aglomerado; IV - detalhar operacionalmente o sistema de transporte público de passageiros no Município de Belém, fixando itinerários, frequências, horários, lotação, equipamentos, turnos 
coletivos, assim como demais medidas sanitárias, como uso de máscara por trabalhadores rodoviários e usuários e disponibilização de álcool em gel.

No entanto, isso não permite afirmar que as empresas concessionárias de transporte coletivo estejam desincumbidas do dever de zelar pelo cumprimento das medidas sanitárias de mitigação dos efeitos da pandemia. Até porque, conforme já expendido acima, as concessionárias de transporte coletivo são imediatamente fiscalizadas pelo Poder Público Municipal e devem zelar pelos encargos e responsabilidades assumidos com a concessão para prestar esse importantíssimo serviço público.

E as empresas concessionárias de transporte coletivo, ao exercerem atos de controle sobre as medidas sanitárias e o número de passageiros que ingressam nos veículos não estão exercendo tipicamente atos de poder de polícia. Nesse sentido, Celso Antonio Bandeira de Melo (2005, p. 759-762) esclarece que não se confundem com a polícia administrativa as manifestações impositivas que, embora limitem as liberdades, decorrem de vínculos ou relações específicas perante o destinatário de sua ação. Por conta disso, não são considerados

\footnotetext{
de trabalho, integração intermodal, locais e tempos de parada e critérios para atendimentos especiais; V estabelecer os esquemas operacionais para o serviço de táxi, definindo custos, equipamentos e locais de estacionamentos; VI - fiscalizar segundo os parâmetros definidos, as operações e a exploração do transporte público de passageiros por ônibus, por táxi e por transportes especiais, promovendo as correções, aplicando as penalidades regulamentares nas infrações e arrecadando valores provenientes de multas; VII - elaborar estudos, executar e fiscalizar a política e os valores tarifários fixados para cada modalidade de transporte público de passageiros; VIII - administrar a execução do regulamento e das normas sobre transporte público de passageiros no Município de Belém; IX - realizar diretamente ou através de terceiros contratados ou convenentes, estudos, pesquisas e trabalhos técnicos requeridos à administração do transporte público de passageiros, e ao aprimoramento técnico e gerencial das empresas operadoras, no Município de Belém; X atuar junto a órgãos públicos e privados no âmbito do Município, do Estado e da União, que atuem sobre os segmentos, que afetam o trânsito e o transporte público de passageiros, visando compatibilizar as ações de interesse comum no Município de Belém; XI - executar as atividades relacionadas com o planejamento, circulação, operação e fiscalização do trânsito e dos transportes urbanos, que em virtude de delegação ou convênio, venham a lhe ser atribuídas por órgão ou entidade da Administração Pública no âmbito da União, do Estado e do Município de Belém e dos demais municípios do aglomerado urbano; XII - coordenar a elaboração de estudos, programas e projetos relacionados com o sistema viário e o sistema de circulação do Município de Belém; XIII - analisar e decidir sobre a implementação de planos e projetos referente a loteamentos, conjuntos habitacionais, qualquer tipo de equipamento urbano, construção ou eventos, que possam vir a influenciar a fluidez do trânsito e o sistema de transporte urbano; XIV - manter sistemas informatizados, capazes de coletar, processar, analisar, e fornecer dados e informações referentes ao Sistema de Transporte Público de Passageiros, em seus aspectos cadastrais, operacionais e econômicos; XV - combater o transporte ilegal de passageiros.

${ }^{10}$ O Supremo Tribunal Federal fixou a tese de repercussão geral 473, pela qual: "É constitucional a atribuição às guardas municipais do exercício de poder de polícia de trânsito, inclusive para imposição de sanções administrativas legalmente previstas" (RE 658570, de 06/08/2015). No que se refere às rodovias federais, além da Polícia Rodoviária Federal, o Superior Tribunal de Justiça, ao fixar a tese de recurso repetitivo 965, entendeu que "O Departamento Nacional de Infraestrutura de Transportes - DNIT detém competência para a fiscalização do trânsito nas rodovias e estradas federais, podendo aplicar, em caráter não exclusivo, penalidade por infração ao Código de Trânsito Brasileiro, consoante se extrai da conjugada exegese dos arts. 82, § 3º, da Lei 10.233/2001 e 21 da Lei 9.503/97 (Código de Trânsito Brasileiro)".
} 
atos de poder de polícia os que atingem usuários de serviços públicos relativamente àquele especial relacionamento, abrangendo aí os deveres do servidor público e as imposições que os concessionários de serviços públicos devem observar e fazer cumprir. Portanto, em tais situações, há um vínculo específico entre o indivíduo e o Poder Público ou o mesmo a concessionário de serviço público, quando o indivíduo se encontra em situação de especial sujeição decorrente de um vínculo mais estrito que revelam uma supremacia mais acentuada. É o que decorre, por exemplo, com o usuário de determinado serviço que se submete à disciplina interna de funcionamento de estabelecimentos como bibliotecas, universidades, onde lhe são imputadas certas regras e imposições restritivas, mas também disposições benéficas. Tais regras se justificam pela necessidade de regular a situação dos que se inserem no âmbito das relações específicas e decorrem de condições elementares do funcionamento de certas atividades.

Em sentido inverso, o Poder de Polícia, além de exercido pela Administração Pública, deve incidir sobre a liberdade e a propriedade, decorrer do interesse público e social e ser fundamentado num vínculo geral. Ausentes quaisquer desses requistos, não haverá ato de polícia, embora possa remanescer como ato administrativo, tal como ocorre com as exigências impostas pelo Poder Público ao permissionário de uso de bem público para que observe horários e condições de funcionamento. Aqui, prevalece uma relação jurídica especial e não um ato de polícia (GASPARINI, 2002, p. 120).

É exatamente esse quadro que se observa na relação jurídica entre a empresa concessionária de transporte coletivo e os usuários e que determina que a primeira imponha aos segundos o cumprimento de determinadas condutas e abstenções. E, nesse momento, não há que se falar em exercício de poder de polícia pela empresa concessionária.

Assim, não podem as empresas concessionárias se eximirem de zelar pelos direitos dos usuários do serviço público ${ }^{11}$, aqui os passageiros, especialmente quando o risco de contágio pela COVID-19 mostra-se tão elevado, notadamente em espaço fechados e com maior densidade de ocupação de pessoas.

\footnotetext{
${ }^{11}$ Destacam-se aqui os direitos e diretrizes estabelecidos na lei federal $13.460 / 17$, art. $5^{\circ}$ e incisos: "VIII- adoção de medidas visando a proteção à saúde e a segurança dos usuários; $\mathrm{X}$ - manutenção de instalações salubres, seguras, sinalizadas, acessíveis e adequadas ao serviço e ao atendimento". Também destacam-se os direitos do usuário do Sistema Nacional de Mobilidade Urbana, previstos no art. 14, da lei federal 12.587/12, especialmente o seguinte: "IV - ter ambiente seguro e acessível para a utilização do Sistema Nacional de Mobilidade Urbana, conforme as Leis 10.048, de 8 de novembro de 2000, e 10.098, de 19 de dezembro de 2000.”
} 
Caso prevalecesse a tese de que o controle sobre a conduta do usuário quanto às medidas de higiene, uso de máscara e distanciamento social apenas poderia ser efetuada por agentes públicos, as empresas não deveriam exercer qualquer controle sobre a conduta dos usuários dentro e no acesso aos veículos coletivos. Mais do que isso, estar-se-ia admitindo que qualquer estabelecimento privado que explore atividade econômica ou preste serviços não poderia empreender qualquer medida de controle e combate à propagação do coronavírus, como limitar o acesso de usuários/consumidores, exigir o uso de máscaras de proteção facial e a higienização de mãos com álcool. Por óbvio, não se pode admitir tal hipótese, sob pena de anuir com um total descompromisso dos entes privados no esforço cooperativo para a implementação de medidas sanitárias e no combate à disseminação do vírus.

\section{A PANDEMIA DE COVID-19 E A NECESSIDADE DE COOPERAÇÃO DAS EMPRESAS CONCESSIONÁRIAS DE TRANSPORTE COLETIVO EM PROL DAS MEDIDAS SANITÁRIAS}

Com o advento da Pandemia de COVID-19, o dever de cooperação dos entes privados com o Estado, tendo em vista o resguardo do interesse público, mormente a preservação da vida e da saúde das pessoas, ganha maior relevo. Tal assertiva implica em situações de excepcionalidade, normativamente deflagradas pelas várias leis e decretos que reconhecerem calamidade pública e estado excepcional ${ }^{12}$ em todas as esferas federativas e pela Emenda Constitucional 106, que institui regime extraordinário fiscal, financeiro e de contratações para enfrentamento de calamidade pública nacional decorrente de pandemia.

Vale ressaltar que, antes mesmo de confirmado o primeiro caso da COVID-19, foi editada a lei 13.979/2020, trazendo as medidas a serem adotadas para enfrentamento da emergência de saúde pública, podendo impor medidas tais como: isolamento; quarentena, determinação de realização compulsória de: exames médicos, testes laboratoriais, coleta de amostras clínicas, vacinação e outras medidas profiláticas; ou, tratamentos médicos

\footnotetext{
${ }^{12}$ Vale ressaltar que a Pandemia de Covid-19 não configura a primeira experiência de limitações de direitos individuais em razão da necessidade de controle de doenças e motivadas pelo interesse público na garantia do direito à saúde. Exemplo disso foram as ações de combate à Dengue, quando foi permitido que o Poder público, inclusive, ingressasse nas residências para fazer o controle da disseminação do mosquito que funciona como vetor da doença. Nesse cenário, em nome do dever de promoção da saúde, os entes federados puderam realizar o controle epidemiológico junto aos imóveis, a fim de conformar o direito à inviolabilidade do domicílio à necessidade de proteção sanitária (PIRES, 2008, p. 313).
} 
específicos; uso obrigatório de máscaras de proteção individual; estudo ou investigação epidemiológica; exumação, necropsia, cremação e manejo de cadáver; restrição excepcional e temporária, por rodovias, portos ou aeroportos, de entrada e saída do País e locomoção interestadual e intermunicipal; requisição de bens e serviços de pessoas naturais e jurídicas, hipótese em que será garantido o pagamento posterior de indenização justa; autorização excepcional e temporária para a importação e distribuição de quaisquer materiais, medicamentos, equipamentos e insumos da área de saúde sujeitos à vigilância sanitária sem registro na ANVISA considerados essenciais para auxiliar no combate à pandemia do coronavírus.

No mais, o art. $3^{\circ}$-A. da lei 13.979/2020 preceitua que é obrigatório manter boca e nariz cobertos por máscara de proteção individual, conforme a legislação sanitária e na forma de regulamentação estabelecida pelo Poder Executivo federal, para circulação em espaços públicos e privados acessíveis ao público, em vias públicas e em transportes públicos coletivos, bem como em: veículos de transporte remunerado privado individual de passageiros por aplicativo ou por meio de táxis; ônibus, aeronaves ou embarcações de uso coletivo fretados; estabelecimentos comerciais e industriais, templos religiosos, estabelecimentos de ensino e demais locais fechados em que haja reunião de pessoas.

Nesse contexto, citando o Ministro Eros Grau, para quem as normas só valem para situações normais e que a normalidade da situação que pressupõem é um elemento básico do seu "valer", Dantas e Dias (2020, p. 170) doutrinam que não é estranha à doutrina a possibilidade de se encontrarem saídas para problemas reais não previstos de forma clara e evidente no direito positivo. A análise do direito comparado também nos permite vislumbrar ocasiões em que soluções programáticas foram adotadas para resolver problemas concretos, como a adoção da chamada "jurisprudência da Crise" pelo Tribunal Constitucional Português. Naquela ocasião, o período de austeridade que o país enfrentava exigiu que o texto constitucional fosse interpretado pela Corte à luz de um novo contexto institucional. Com isso, dadas as circunstâncias e suas exigências, foram admitidas medidas legislativas excepcionais que, em tempos de normalidade, teriam tido sua inconstitucionalidade declarada.

Em razão disso, José Roberto Afonso (2020, p. 160) chega a admitir que, para o enfrentamento da situação de calamidade pública hoje vivenciada, seria possível a requisição compulsória de bens e serviços, ações típicas de estado de guerra. Ora, se até medidas mais 
severas são cabíveis dada a excepcionalidade vivida, como cogitar que as empresas concessionárias do transporte coletivos de passageiro se furtem a colaborar para mitigar os efeitos do contágio em massa da população, ainda que, para isso, venham a interpelar e controlar seus usuários?

Nesse diapasão, cabe ressaltar que a saúde pública, como integrante da seguridade social, consiste no conjunto integrado de ações de iniciativa dos Poderes Públicos e da sociedade, nos termos do art. 194 da CF/88. De igual forma, cabe ao Poder Público dispor sobre as ações e serviços de saúde, sobre sua regulamentação, fiscalização e controle, devendo sua execução ser feita diretamente ou através de terceiros e, também, por pessoa física ou jurídica de direito privado. Ou seja, as políticas de saúde, embora precipuamente a cargo do Estado, não exclui os deveres das pessoas, família, das empresas e da sociedade, conforme preconiza o art. $2^{\circ}, \S 2^{\circ}$, da lei nacional 8.080/1990, a lei orgânica do Sistema Único de Saúde. Assim, as instituições privadas poderão participar do SUS de forma complementar, obedecidas as mesmas diretrizes do sistema e em sintonia com o conceito extensivo de saúde da Organização Mundial da Saúde, como um estado de completo bem-estar físico, mental e social, não apenas ausência de doença e que foi recepcionado pelo art. $3^{\circ}$ da Lei 8.080/94. (AMADO, 2021, p. 55).

Neste contexto, a participação de agentes públicos e privados para a efetivação do direito à saúde deve ser balizada pelos princípios da justiça social. Por meio deles, serão definidos e ajustados os critérios de organização para permitir a divisão de vantagens na sociedade e a forma de atribuir direitos e deveres nas instituições básicas e definidoras da distribuição apropriada dos benefícios e encargos da cooperação social (LAMARÃO NETO, 2019, p. 133).

Aplicando esse dever de atuação conjunta do Estado, das empresas privadas e dos indivíduos nas medidas de prevenção à COVD-19, no Estado do Pará, o decreto estadual 800, de 31 de março de 2020, na versão consolidada e publicada no Diário Oficial do Estado do Pará 34.474 de 28.01.2021, determina que: "todos os trabalhadores e clientes devem usar máscaras de proteção, que devem ser trocadas de acordo com as instruções do fabricante e as indicações dos órgãos sanitários de saúde no transporte, seja coletivo ou individual, e nos ambientes públicos e de convívio social”, em todas as fases de bandeiramento, com exceção da azul. 
Cabe ressaltar que a imposição do uso de máscaras e limites à fruição dos direitos individuais por Estados e Municípios como medidas excepcionais de combate à pandemia estão devidamente amparados pelo Supremo Tribunal Federal, em decisão preferida na ADI 6341 MC/DF. Nessa direção, cabe ressaltar entendimentos de tribunais estaduais que confirmam mais concretamente a possibilidade de imposições dessa natureza, conforme ementas selecionadas:

DIREITO ADMINISTRATIVO. MANDADO DE SEGURANÇA. DECRETO N ${ }^{\circ}$ 40.648/2020 - DF. OBRIGATORIEDADE DO USO DE MÁSCARA DE PROTEÇÃO FACIAL. ÂMBITO DO DISTRITO FEDERAL. COVID-19. PRELIMINAR DE AUSÊNCIA DE INTERESSE RECURSAL. REJEIÇÃO. MEDIDAS DE COMBATE À COVID-19. COMPETÊNCIA CONCORRENTE. DIREITO À VIDA E À SAÚDE. PREPONDERÂNCIA. 1. Verifica-se a ocorrência de interesse processual quando o impetrante de mandado de segurança alega que decreto distrital ofende direito líquido e certo seu, ainda que haja pedido subsidiário de extensão dos efeitos da decisão para a coletividade de moradores do Distrito Federal. 2. Conforme entendimento do STF, medidas adotadas pelo Governo Federal no combate à Covid-19 não afastam a competência concorrente de estados e municípios para criar normas locais de combate e prevenção. 3. No conflito entre um direito individual, no caso locomover-se em áreas públicas sem o uso de máscara facial, e o interesse coletivo, consubstanciado na preservação da vida e da saúde, deve prevalecer aquele que atende à coletividade. 4. Preliminar de ausência de interesse processual rejeitada. Segurança denegada.

(TJ-DF 07117664220208070000 DF 0711766-42.2020.8.07.0000, Relator: SEBASTIÃO COELHO, Data de Julgamento: 01/09/2020, Conselho Especial, Data de Publicação: Publicado no PJe : 16/09/2020 . Pág.: Sem Página Cadastrada.)

MANDADO DE SEGURANÇA. USO DAS MÁSCARAS. CORONAVÍRUS. IMPOSIÇÃO. EMERGÊNCIA SANITÁRIA Decreto n 64.959, de 4.5.2020, do Governador de S. Paulo. Obrigatoriedade do uso das máscaras faciais. Suposta violação dos arts. $5^{\circ}$, II e 84, da CF. Súmula 266 do STF. Não conhecimento. Superação do ponto pelo emprego do quanto posto no art. 282 , $\S 2^{\circ}$ do NCPC. Julgamento pelo mérito. Decreto do Governador que obriga o uso das máscaras faciais. Alegação de ausência de lei precedente. Inocorrência. Hipótese de competência concorrente de todas as instâncias administrativas, o que restou afirmado pelo col. STF. Decreto do Governador exarado em sintonia com a Lei Federal $\mathrm{n}^{\circ}$ 13.979, de 6.2.2020, seu art. $3^{\circ}$, III, letra d. Tema evidentemente afeto ao poder de polícia sanitária, em consonância com o disposto no art. 78 da Lei Federal $n^{\circ}$ 5.172/66. Máscaras que, segundo os epidemiologistas, têm relevância estratégica na prevenção contra a contaminação pelo coronavírus, especialmente na fase de aceleração da pandemia, de molde a impedir a veiculação do patógeno, servindo de suplemento ao distanciamento social quando não possível. Recrudescimento da contaminação em novembro passado. Denegação da segurança.

(TJ-SP - MS: 21656012920208260000 SP 2165601-29.2020.8.26.0000, Relator: Costabile e Solimene, Data de Julgamento: 27/01/2021, Órgão Especial, Data de Publicação: 28/01/2021)

EMENTA: AGRAVO DE INSTRUMENTO - MANDADO DE SEGURANÇA FUNCIONAMENTO DE ESTABELECIMENTOS COMERCIAIS DURANTE O 
PERÍODO DE SITUAÇÃO DE PANDEMIA ("COVID-19") - MUNICÍPIO DE BELO HORIZONTE - DECRETO MUNICIPAL N $\mathrm{N}^{\circ} 17.328 / 2020$ REGULAMENTAÇÃO E FUNCIONAMENTO DAS ATIVIDADES COMERCIAIS - TUTELA AOS DIREITOS DA SAÚDE E VIDA DA POPULAÇÃO - COMPETÊNCIA DO ENTE PÚBLICO MUNICIPAL RESTRIÇÃO À ATIVIDADE ECONÔMICA - CABIMENTO - PODER DE POLÍCIA - LIMINAR - INDEFERIMENTO - REQUISITOS AUSENTES DECISÃO MANTIDA. 1. Para a concessão de liminar em Mandado de Segurança é necessária a presença dos pressupostos previstos no inciso III do artigo $7^{\circ}$, da Lei Federal $\mathrm{n}^{\circ} 12.016 / 2009$, consubstanciados no fumus boni iuris e no periculum in mora, que devem ser de plano demonstrados. 2. De acordo com o entendimento do Supremo Tribunal Federal, é assegurado aos Governos Estadual, Distrital e Municipal, no exercício de suas atribuições e no âmbito de seus territórios, a competência para a adoção ou manutenção de medidas restritivas durante a pandemia da "COVID-19". 3. No âmbito do Município de Belo Horizonte, o Decreto $\mathrm{n}^{\mathrm{o}}$ 17.328/2020 suspendeu "por tempo indeterminado os Alvarás de Localização e Funcionamento e autorizações emitidos para todas as atividades comerciais", à exceção de serviços essenciais e indispensáveis à população. 4. O Ente Público Municipal pode estabelecer restrição e suspensão das atividades comerciais em situações de emergência pública, cuja atribuição decorre de seu Poder de Polícia. 5. Deve ser mantido o indeferimento da liminar em sede de Mandado de Segurança em razão da ausência de demonstração, de plano, do requisito do fumus boni iuris.

(TJ-MG - AI: 10000204433072001 MG, Relator: Elias Camilo, Data de Julgamento: 20/08/2020, Data de Publicação: 21/08/2020)

Especificamente, destacam-se julgados dos Tribunais de Justiça de Rondônia e do Mato Grosso que reconhecem, como dever de cooperação e responsabilidade dos entes privados, também realizarem controle sobre o comportamento dos usuários de seus estabelecimentos prestadores de serviços públicos e de exploração de atividade econômica, sem prejuízo do recurso às forças de segurança e fiscalizatórias do Poder Público. Vale observar as ementas:

Agravo de instrumento. Situação de pandemia em saúde pública. Instituição financeira. Organização de fila externa. Possibilidade. Multa cominatória. Valor razoável. Manutenção. Recurso desprovido. Por mais que o encargo e a responsabilidade para cuidar dos espaços públicos, externo às agências, seja do Estado, detentor do poder de polícia, capaz de obstar aglomerações de pessoas, em caso de pandemia em saúde pública, há a necessidade de união de forças, no sentido de, ao menos, a orientação das pessoas menos esclarecidas ou que não se importam com os riscos e que desejam o acesso na agência. As astreintes devem ser fixadas em patamar razoável e condizente com o seu caráter inibitório, de modo que não demonstrada a disparidade, a pretensão recursal não merece acolhimento.

(TJ-RO - AI: 08036149320208220000 RO 0803614-93.2020.822.0000, Data de Julgamento: 02/12/2020)

AGRAVO DE INSTRUMENTO - AÇÃO CIVIL PÚBLICA- MEDIDAS DE PREVENÇÃO AO COVID - FILAS EM INSTITUIÇÕES BANCÁRIAS DISTANCIAMENTO SOCIAL - PRELIMINAR: ILEGITIMIDADE ATIVA DA 
DEFENSORIA PÚBLICA - APLICAÇÃO DE MULTA DIÁRIA IMPOSSIBILIDADE DE REDUÇÃO - MEIO COERCITIVO PARA CUMPRIMENTO DA DETERMINAÇÃO JUDICIAL - RECURSO DESPROVIDO. "A Defensoria Pública possui legitimidade ativa ad causam para propor ação civil pública em nome próprio com o objetivo de defender interesses difusos, coletivos em sentido estrito e individuais homogêneos de consumidores lesados em razão de relações firmadas com as instituições financeiras. Precedentes. STJ e STF" (AgRg no REsp 1.572.699/MT, Rel. Ministro Marco Buzzi, Quarta Turma, julgado em 17/05/2016, DJe 24/05/2016). A supervisão e orientação adequadas das filas, com organização voltada ao distanciamento mínimo entre as pessoas, exigido na decisão recorrida, indicado por marcações no piso, é medida básica a ser tomada por todos os estabelecimentos, que atraiam grande número de clientes no atual momento de pandemia. Além disso, cabe destacar a existência de norma de autorregulação da Federação Brasileira de Bancos (Febraban), que estipula limite máximo de 20 minutos de espera em filas de agências bancárias, regulamentação essa que, em tempos de pandemia e emergência de saúde pública, deveria ser, ainda em maior medida, aplicada à risca: A determinação de regularização das filas no ambiente externo da agência não ultrapassa o limite da razoabilidade ou implica no exercício de poder de polícia típico da Administração Pública, posto que tão somente determina que se faça a orientação de seus usuários, adotando medidas de sinalização e utilização de "meios compatíveis e aptos para se manter o distanciamento, disponibilizando tantos servidores quanto for necessário para o cumprimento da medida", sem empecilho que a agência bancária acione as autoridades públicas competentes para dar cumprimento. Em que pese o pedido de extirpação ou redução da multa fixada, entendo que estes não devem ser acolhidos, considerando que o astreinte serve como meio coercitivo para o cumprimento da determinação judicial, a qual visa salvaguardar a saúde dos munícipes que utilizam dos serviços disponibilizados pela instituição bancária, possuindo caráter pedagógico. Agravo desprovido.

(TJ-MT 10111152320208110000 MT, Relator: MARIA EROTIDES KNEIP BARANJAK, Data de Julgamento: 19/10/2020, Primeira Câmara de Direito Público e Coletivo, Data de Publicação: 28/10/2020)

O fato de serem atribuídas responsabilidades às concessionárias de serviço público e exploradores de atividades econômica de averiguar condutas indevidas e orientar a sua correção aos usuários não implica em invasão pelo particular do Poder de Polícia reservado ao Estado.

Não obstante isso, é razoável e crível que o Poder Público Municipal oriente e fiscalize as empresas concessionárias de transporte coletivos de passageiros a zelar e cumprir as medidas de combate à Pandemia de Covid-19 no interior dos veículos, ainda que, para isso, tenham que admoestar os usuários quanto ao uso de máscaras e limitar o acesso destes ao interior do veículo. Sem prejuízo disso, as Autarquias Municipais, a Guarda Municipal, a Polícia Militar e demais agentes públicos competentes devem cooperar com as referidas empresas no cumprimento deste mister, por meio de ações como rondas no interior dos coletivos e nas paradas de ônibus, além de prestarem suporte repressivo perante os usuários que resistirem ou violarem as exigências sanitárias. Mais ainda: os agentes públicos devem 
estar à disposição das empresas de transporte coletivo para, em todas as vezes que se fizer necessário, empregar legalmente o uso da força e impor sanções aos usuários que estejam em descumprimento às medidas sanitárias necessárias durante a Pandemia de COVID-19.

\section{CONSIDERAÇÕES FINAIS}

Conforme fartamente vivenciado nos últimos anos - e ainda sem previsão de término - o mundo e, particularmente o Brasil, vem sendo assolados por uma crise sanitária, social e econômica sem precedentes nos últimos cem anos, provocada pela Pandemia de COVID-19. Em que pese as ações mais robustas, notadamente no âmbito da saúde pública, caibam ao Poder Público, os particulares não podem se eximir a contribuir, individual e coletivamente, para tentar mitigar a propagação desse vírus que tantos danos pessoais, emocionais e materiais têm causado à população.

Por conta disso, se justificam as medidas restritivas de controle sanitário que impõe o uso de máscaras e que tentam coibir as aglomerações. Tais atos são precipuamente impostos pelo Poder Público aos indivíduos e empresas, configurando o exercício típico do poder de polícia administrativa, inclusive com a possibilidade de sanções pecuniárias e restritivas das atividades econômicas.

No tocante às empresas que exploram o transporte coletivo, essas são fiscalizadas pelas entidades municipais para que zelem pelo bom funcionamento dos serviços, mas acima de tudo para que os ônibus não se tornem vetores de disseminação do coronavírus entre os usuários. Tais objetivos passam, necessariamente, pelo controle da conduta dos próprios usuários, tanto no que se refere ao uso de máscara, mas, principalmente, pela limitação de acesso aos veículos, a fim de evitar superlotação. Em que pese o necessário apoio dos agentes de trânsito, dos guardas municipais e da Polícia Militar para exercer esses controles sobre a população, não tão somente no interior dos ônibus, mas também nos pontos e terminais, as empresas concessionárias não podem se furtar a colaborar com a efetivação dessas medidas de controle sanitário.

Ao exigir esse tipo de condutas e abstenções dos usuários, as empresas não estão a exercer o poder de polícia, inerente ao Estado. Na realidade, os agentes privados estão aí implicados nas relações específicas do vínculo administrativo que marcam a concessão do 
transporte coletivo para sua exploração. Isso porque, como sabido, as concessionárias devem zelar pelo interesse público, notadamente a preservação da saúde dos usuários e da coletividade, justamente para que os riscos de exposição e contágio nos ônibus sejam mitigados.

Por fim, vale ressalvar que não se pode sobrecarregar os particulares quanto aos encargos das tão relevantes medidas sanitárias, tampouco ignorar as dificuldades econômicas e materiais que possam apresentar para fazer valer tais atos. Por isso, as imposições às empresas concessionárias podem ser conjugadas com auxílios por parte do Poder Público, tais como benefícios fiscais e subsídios, assim como o apoio material dos agentes de trânsito e de segurança. Em tempos de pandemia, mais do que nunca, a palavra de ordem deve ser: cooperação.

\section{REFERÊNCIAS BIBLIOGRÁFICAS}

AFONSO, José Roberto. Orçamento de guerra: conceituação fiscal. In: MENDES, Gilmar Ferreira; SANTANA, Hadassah Laís; AFONSO, José Roberto (Coord.). Governance 4.0 para Covid 19 no Brasil: propostas para a gestão pública e para políticas sociais e econômicas. São Paulo: Almedina, 2020.

AMADO, Frederico. Manual de Direito Previdenciário. Salvador: Juspodivm, 2021.

BANDEIRA DE MELO, Celso Antônio. Curso de Direito administrativo. 19. ed. São Paulo: Malheiros, 2005.

CARVALHO FILHO, José dos Santos. Manual de direito administrativo. 32. ed. rev., atual. e ampl. São Paulo: Atlas, 2018.

DANTAS, Bruno \& DIAS, Frederico Carvalho. O orçamento de guerra como solução de adaptação do arcabouço institucional para o combate à pandemia. In: MENDES, Gilmar Ferreira; SANTANA, Hadassah Laís; AFONSO, José Roberto (Coord.). Governance 4.0 para Covid 19 no Brasil: propostas para a gestão pública e para políticas sociais e econômicas. São Paulo: Almedina, 2020.

GASPARINI, Diogenes. Direito Administrativo. 7. ed. São Paulo: Saraiva, 2002.

JUSTEN FILHO, Marçal Justen. Curso de direito administrativo. 8. ed. Belo Horizonte: Fórum, 2012. 
LAMARÃO NETO, Homero. Judicialização da saúde a partir da EC 45. In: TEIXEIRA, Eliana Franco; FERREIRA, Vanessa Ferreira (Org.). A crise da proteção social no Brasil: a igualdade na filosofia política contemporânea. Rio de Janeiro: Lumen Juris, 2019.

MEDAUAR, Odete. Direito Administrativo Moderno. 21. ed. Belo Horizonte: Fórum, 2018.

MEIRELLES, Hely Lopes. Direito administrativo brasileiro. Atualizado por: Eurico de Andrade Azevedo, Délcio Balestero Aleixo e José Emmanuel Burle Filho. 30. ed. São Paulo: Malheiros, 2005.

PIRES, Luis Manoel Fonseca. O controle epidemiológico da dengue e a inviolabilidade do domicílio. In: MARINELA, Fernanda; BOLZAN, Fabrício. Leituras complementares de direito administrativo. Salvador: Juspodivm, 2008.

TÁCITO, Caio. O poder de polícia e seus limites. In: TÁCITO, Caio (Org.). Direito administrativo. São Paulo: Saraiva, 1975. 